\title{
The Impact of Teaching Questioning on the Iranian EFL Learners' Problem-solving in Writing
}

\author{
Amir Marzban \\ Department of English Language, Islamic Azad University, Qaemshahr Branch, Qaemshahr, Iran \\ Zahra Jalili (Corresponding Author) \\ Department of TEFL, Mazandaran Science \& Research Branch, Islamic Azad University, Mazandaran, Iran
}

\begin{abstract}
This study was an attempt to gain an insight into Iranian EFL learners' problem-solving when writing in English. To do so, the possible impact of developing Iranian EFL learners' level of critical thinking on their problem-solving while writing in English was investigated. Problem-solving in writing was examined on the formulation stage of writing from two aspects: frequency of solving formulation problems, and the amount of time devoted to solving formulation problems in general, and more specifically, as a function of the type of problems (i.e. upgrading/ compensatory class of problems). Critical thinking was developed through teaching the learners how to ask and answer questions in English. Learners practiced asking and answering questions in English about the content of their course book using keywords and sample question stems from Bloom's (1956) taxonomy of educational objectives (cognitive domain) in six weeks. The results have shown that the treatment of the study is effective in increasing the level of critical thinking. The treatment also leads in spending more time on problem-solving formulation. Teaching questioning also leads to the devotion of more time to upgrading rather that compensatory class of problems. However, the treatment did not have any significant effect on the frequency of solving formulation problems.
\end{abstract}

Index Terms-EFL learner, problem-solving formulation, writing, critical thinking, upgrading class of problems, compensatory class of problems

\section{INTRODUCTION}

As a basic communication means, writing is an important language skill among other three major skills. Writing in a second/ foreign language is considered to be vital for the learners as well. Different groups of second/ foreign language learners require writing skill for different purposes and for this means, they make use of various text types.

Writing is a multi-dimensional activity. Experts view writing as consisting of social, cultural, and cognitive aspects. From a cognitive view point, writing is viewed as a problem solving task (Munchó n, 2001; Roca de Larios \& Murphy, 2001). Despite the importance of writing, this skill had been viewed as a process of just translating ideas into words according to a set of grammar rules before the 1970s when Emig (1971; cited in Dyson \& Freedman, 1990) first questioned this set of practices and, in fact, launched the process-oriented approach to writing.

Since Emig (1971), the researchers have continued studying the writers' thought processes. While trying to do so, they began to produce a model or parts of a model for the process of producing written language (Freedman, Dyson, Flower \& Chafe, 1987).

One very important achievement of those researchers working on the process-oriented approach to writing was adopting a problem-solving view point regarding the writing activity. They concluded that the writing process is a hierarchically organized, goal-oriented, problem-solving process; and that writers at different levels face the problems in writing differently. More precisely as Munchó n (2001) states "a problem exists when (i) an information processing system experiences a gap between a self-imposed or other-imposed initial state and an intended goal state; and (ii) the gap cannot be bridged without a search process" (p.9).

The writers' problem-solving process begins actually with their attempts to define precisely their topic and goals for the essay. The writers should also elaborate their problem representation to include their audiences' requirements and expectations, a process that continues throughout the writing process. More precisely, moment to moment, the writer is involved in problem solving since the writer faces a host of potential problems from time to time he/ she decides to write on a special topic which continues all through the time when the writer is actually involved in the act of writing in the form of "a series of non-linear jumps from one problem and procedure to another" (Flower and Hayes, 1977, p. 460). In other words, this is not the case that the writers first do planning for their writing, then they write the whole text and finally they start to revise the whole text, but the writers are involved in planning, formulation, and revision all through the writing process. This "process of converting thoughts into language" which is referred to as the formulation process (Roca de Larios, Munchó n, \& Murphy, 2006, p.1) is the focus of the present study. The formulation process involves, 
on the one hand, "the conjugation of goals and ideas with the constraints of syntax and lexis" (Fayol, 1991; cited in Roca de Larios, Munchó n, \& Murphy, 2006), and, on the other hand, the production of sentences and their integration into a textual framework (Roca de Larios, Murphy, \& Munchó n, 1999). This means that while producing texts, writers are often involved in decision-making and problem-solving behavior since they need to "juggle and integrate the multiple constraints of their knowledge, their plans, and their text into the production of each new sentence" (Flower \& Hayes, 1981, p. 371).

To examine the writers' problem-solving behavior, experts usually focus on one stage for instance planning, formulation, or revision. Since these processes are not linear, they devise ways to distinguish among these processes while the writers are involved in the writing activity.

Regarding the issues mentioned so far, the present study is an attempt to investigate whether teaching critical thinking through the key skill of asking and answering questions based on Bloom's (1956) Taxonomy of Educational Objectives (cognitive domain), has any statistically significant effect on the Iranian EFL learners' frequency (number of times) and duration (the amount of time spent) of solving formulation problems.

The present study was run in an attempt to answer the following questions:

1) Does "teaching questioning" as a critical thinking skill have any statistically significant effect on the Iranian EFL learners' level of critical thinking?

2) Does "teaching questioning" as a critical thinking skill have any statistically significant effect on the amount of time devoted to solving formulation problems by the Iranian EFL learners when writing in English?

3) Does "teaching questioning" as a critical thinking skill have any statistically significant effect on the frequency of solving formulation problems by the Iranian EFL learners when writing in English?

4) Does "teaching questioning" as a critical thinking skill have any statistically significant effect on the amount of time the Iranian EFL learners devote to problem-solving formulation as a function of the type of problems (i.e. upgrading/ compensatory class of problems) they pose themselves?

So far, researchers have conducted studies comparing the language learners' problem-solving behavior in the formulation process in L1 and L2 writing; however, as Roca de Larios, Munchó n, \& Murphy (2006) point out, scant attention has been paid to finding way(s) to make learners better problem-solvers as they face problems while converting their thoughts into language as they write in a language other than their mother tongue. Bensely (1998) states that as writers struggle to write what they think, they are actually involved in critical thinking so improving the language learners' critical thinking might help them in facing problems in the process of converting thoughts into language which means a better performance in the formulation process of writing.

\section{REVIEW OF LITERATURE}

\section{A. The Process Oriented Approach}

As mentioned earlier a process oriented approach to writing is adopted for the purpose of the present study. The research movement known as "process writing" emerged with the aim of achieving a deeper insight into the mental processes writers engage in while writing (Munchón, 2001). "The cognitively-oriented trend within the process tradition views composition writing as a goal oriented, cognitively-demanding, problem-solving task" (Bereiter \& Scardamalia, 1987; Flower and Hayes, 1980, 1981a, 1981b; Hayes, 1996; Hayes \& Flower, 1980; Scardamalia \& Bereiter, 1987; Torrance \& Jeffery, 1999; as cited in Munchón, 2001).

\section{B. Problem-solving and Writing}

So far, it is mentioned that a process oriented approach to writing is adopted in the present study; one which many scholars namely, Bereiter \& Scardamalia, Flower \& Hayes, Munchón and other experts sharing the same view point regard it as a problem solving framework to writing activity. Regarding the order of writing, in fact, a writer may start writing a paragraph, deciding which word or grammatical structure to use (each is considered as a potential problem), writing some words and then reading one's sentence, deciding to revise the recently written words immediately after writing them or even before actually putting one's thought in words. This is the fact of writing which confirms Flower and Hayes (1977) as they consider writing as "a series of non-linear jumps from one problem to another" (p.460).

The writer should also make decisions about the form of one's text in relation to one's goals which he/she had considered in defining one's problem on one hand and goal for reader, self, and text on the other hand.

\section{Problem-solving in the Formulation Stage of Writing}

As far as the researcher studied, most of the research studies done on the problem solving formulation behavior while writing have focused on comparing this behavior between L1 and L2. These studies have been categorized by Roca de Larios, Munchón \& Murphy (2006) into two groups: 1) the concept of writing fluency as a measure of problem-solving behavior, and 2) the nature of the actual problem solving behavior that L2 writers are involved in during writing.

The number of words written, the number and length of pauses, and the interruption of the actual writing process by other processes are the issues considered in most of the studies carried out comparing L1 and L2 composing processes focusing on the issue of fluency. The results of the studies confirm the influence of the labour-intensive L 2 writing process on the fluency. As Roca de Larios, Munchón \& Murphy (2006) point out, the results of the studies in this field 
show that in the L2 situation, writers tend to: produce fewer words in their written texts; find it harder to keep the writing process constant according to the higher number of pauses, the interruption of the actual formulation processes by other processes, and also by producing fewer words between pauses.

The studies run in the field of problem-solving behavior have revealed contradictory findings regarding the similarities and differences between the problem solving nature of formulation processes in L1 and L2; some studies have supported the existence of differences between L1 and L2 formulation processes, while some other studies point out similarities in writers' problem solving behavior across languages (Roca de Larios, Munchón \& Murphy, 2006).

Simply asserting that the L2 limits the formulation of ideas may be more of a generalization if we can't properly qualify the claim. In this vein, a research which could be of interest is one done by Roca de Larios et al. (2001) in which he examined the temporal distribution of formulation processes in L1 and L2 writing among Spanish EFL learners at different proficiency levels. The results of this study showed both cross-linguistic similarities and differences within the same group of writers. The equal amount of time of the total composing time (around 70\%) was allocated to formulating both, the L1 and L2 texts; however, the results also supported the existence of greater problem solving activity in L2 formulation processes.

\section{METHODOLOGY}

\section{A. Subjects}

To fulfill the purpose of the present study, 60 participants chosen based on intact group design from a sample of 100 male and female EFL learners took part in the study. They were from a language institute in Tehran who were EFL learners at the intermediate level. They were between 20 to 30 years old. To check the participants' proficiency level, an intermediate Nelson proficiency test (200 A) was administered. The Nelson proficiency test (200 A) was standardized by the researcher in a pilot group of 30 and the reliability was found to be 0.78 . They were then randomly assigned to control and experimental groups.

\section{B. Procedure}

This study was conducted in four phases; in the first stage, the preparation stage besides piloting the proficiency test and the critical thinking questionnaire, the handouts were provided to be used in the treatment stage. Bloom's taxonomy of educational objectives (cognitive domain, 1956) has six hierarchical levels including knowledge, comprehension, application, analysis, synthesis, and evaluation. For each level, specific keywords and sample questions along with a brief explanation about the content and purpose of each level have been defined. The participants were provided with the materials related to each level, in the form of handouts prepared by the researcher in order to practice asking and answering questions in English. Six handouts were provided for the six levels of Bloom's taxonomy (1956) which was practiced in six weeks of treatment. Also, the participants practiced the think-aloud protocol with a mock composition in the preparation stage. This trial did not include any modeling on the part of the researcher so as not to influence the participants' thought processes (Smith, 1994; cited in Roca de Larios, Munchó n, and Murphy, 2006) or their choice of the language for their verbalizations, especially in L2 condition (Sasaki, 2000). The participants were given the following instruction which was originally in Farsi:

Today I want you to write a composition on ("Advantages and disadvantages of...). While writing, I want you "to say aloud anything and everything that comes through your mind. You should do everything that you would normally do when writing a composition, the only difference being that today you are going to do it talking aloud. You may use whatever language you normally use when writing" -English or Farsi. You will have a maximum of 1 hour to complete the task (adopted from Roca de Larios, Munchó n, and Murphy, 2006).

There was no recording for this trial session.

The second stage, the pre-test stage, included the administration of the piloted proficiency test and the critical thinking questionnaire (the reliability indices were found to be .78 and .88 respectively), and doing the writing task.

Regarding the writing task, one session after the trial session the participants of the study who had practiced the think-aloud protocol before, were asked to do the same task as they did in the trial session, this time with a different topic which was an IELTS exam writing topic. The same instructions as in the trial session were given to the participants. The participants were asked to bring their cellphones in order to record their voices. When they were busy on the task, the researcher was also present to answer their questions or sometimes to remind them to say what they think when they were silent and forgot to talk, but there was no modeling on the part of the researcher. The participants in each group did the writing task on the same session; the researcher decided on this procedure for practical reasons (i.e., the impossibility of recording 30 participants individually due to the lack of resources; and to prevent the participants from revealing their assignments to one another in case they were recorded separately) on the other hand, as Roca de Larios, Munchó n, and Murphy (2006) point out, such procedure has the additional advantage of causing less interaction between the researcher and the participants, as a result "neutralizing variations in the protocol data due to researcher bias (p.104). After finishing the task, the writings and the voice files were collected.

The third stage, the treatment stage, The treatment process lasted for six weeks, three sessions each week. Every week, questions referring to one level of Bloom's taxonomy (1956) was practiced using the handouts containing the 
keywords, sample question stems and a brief explanation about that level (Appendix E) which were put together using Bloom (1956), Brown (2001), and Dalton \& Smith (1986).

In the treatment process, asking and answering questions in English, about the lessons studied during the week, was taught and practiced in a hierarchical order based on Bloom's taxonomy of educational objectives (cognitive domain) (1956). The six levels included knowledge, comprehension, and application which were worked on during the first three weeks or the first half of the treatment process, one level each week, and analysis, synthesis, and evaluation were worked on during the last three weeks or the second half of the treatment process, one level each week as well.

At the first session of each week, the related handout was distributed among the participants in the experimental group. The students read the content of the handout so the researcher could make sure they understood the application of keywords and question stems through providing them with explanations and examples where necessary.

After that, the participants were asked to start writing their questions based on the new lesson of their course book one lesson was often taught each session -using the keywords and question stems in their handouts.

Then they made groups of 2 people and practiced asking and answering their questions in pairs. While the participants were busy on their pair work, the researcher was present, monitored them and answered their questions. After that, they were merged to groups of 4 or 5 and practiced asking and answering each other's questions in larger groups. Finally, each group chose one of their questions to be asked in the classroom. At each stage, the participants had to observe a time limit of about 10 minutes.

This process was repeated in the next two sessions of the week with the new lesson they studied each session.

This process was only for the experimental group which took 30-45 minutes for each session. The treatment process took 18 sessions. The participants in the experimental group studied similar units of the course book in the equal amount of time without receiving the treatment.

The last stage, the post-test stage the same critical thinking questionnaire was administered. Also there was the writing task; the second topic was also an IELTS writing topic. The researcher chose similar topics for the pre-test and post-test (both from the same category, dealing with the problems of studying and living outside of one's own city/country, presumed to be familiar to the participants) in order to prevent the possible influence of the topic of composition on the quality and quantity of writing (Hamp-Lynos, 1990; Sasaki \& Hirose, 1996). This choice was also based on the research evidence that topic familiarity can enhance the writer's involvement in the task (Friedlander, 1990; Gaskill, 1986; cited in Roca de Larios, Munchó n, and Murphy, 2006).

This time also, the participants' voices were recorded using their own cellphones or other devices in the same way as it was done for the pre-test stage with a six week time interval. Then the writings and voice files were collected to be used as the data for the study.

\section{RESULTS AND DISCUSSION}

The results from the critical thinking questionnaire and the transcripts of the think-aloud protocol provided the data for this study. Regarding the questionnaire, the results of the independent $\mathrm{t}$-test $(\mathrm{t}(58)=3.45, \mathrm{P}=.001<.05, \mathrm{r}=.41$ it represents a moderate to large effect size) indicate that there is a significant difference between the experimental and control groups' mean scores on posttest of critical thinking. It shows that the treatment of the study, teaching how to use English language to ask and answer questions, increased the participants' level of critical thinking in experimental group.

Regarding the data from think-aloud protocol, the method of transcription and analysis of formulation in the present study, follows the seminal study by Roca de Larios, Munchó n, and Murphy (2006). The participants' verbalizations were transcribed in the ordinary writing system and the duration of pauses were indicated in parentheses. In order to separate the produced text, re readings, and revisions from other verbalized thoughts in the protocol, the transcripts were also coded according to the following coding system from Roca de Larios, Munchó n, and Murphy (2006) which is also exemplified in Excerpt 1:

a) Distinction of the written text (underlined) from the processes which generate it.

b) Distinction of repetitions/ re readings (in italics).

c) Annotations of any revisions made to the written texts.

Ok...different culture... different culture,... different educational (3) educational system... different educational system, and... different culture, different educational system... and different (2) social problems... and different social problems social problems are temporary... social problems are temporary... are temporary? (4) social problems are temporary (3) no... 2) فكر كنم كه بهتره بكيم are transitory [CROSSES OUT "temporary"] social problems are transitory... yes, it's better... social problems are transitory ok.

The next step was to distinguish formulation from planning and revision. In order to differentiate between formulation and planning, a coding of planning was considered for segments where operations entailing ideas, aims, and so forth, were observed being developed at a pre-linear level while formulation was assigned to those segments where utterances were produced that were clearly included in the text because of their strictly linear character (for instance, lexical units, syntactic structures, etc.). The distinction between formulation and revision was made due to "the distance between the point where the text had originally been written and the point where the change was made." (Roca de Larios, Munchó n, \& Murphy, 2006). Formulation was recognized as the modifications to the sentence being written; 
however, those modifications which were made to the sentences that had already been finished was categorized as revision.

Regarding the analysis of formulation, two classes of formulation problems were recognized: Compensatory class of problems, and Upgrading class of problems (Roca de Larios, Munchó n, \& Murphy, 2006).

The upgrading class of problems, as exemplified in Excerpt 2, "they are problems resulting from an effort to upgrade the expression of meaning or to find a better match between intention and expression or both" (Roca de Larios, Munchó n, \& Murphy, 2006).

EXCERPT 2

But after some time, the students should get used to the new educational system (4) should get used to... (3) بعى بايد

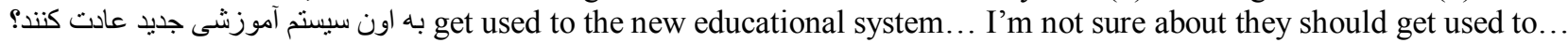
درو اقع نبايد عادت كنند جون عادت كردن بيشتر حالت غير ار ادى دارد اما...منظور من بيشتر اين هست كه اونها بايد درواقع خودشون رو تطبيق بدهند... yes! Its better! So...adapt... but after some time the students should... adapt themselves to the new educational system.

The compensatory class of problems, exemplified in Excerpt 3, "are problems derived from lack of (automatic) access to linguistic knowledge required to express the intended meaning." (Roca de Larios, Munchó n, \& Murphy, 2006). Also, according to DeKeyser (2001, cited in Roca de Larios, Munchó n, \& Murphy, 2006), lack of access to linguistic knowledge is actually a cover term which refers to "communicative situations in which the knowledge required is not retrievable either because it has not been acquired or because it has not been proceduralized/ automatized".

EXCERPT 3

When you don't know the language of that country... you (4) I want to say

مى ...

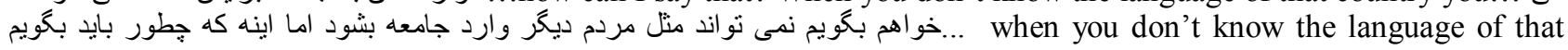
country... you can't join the society.

The results show that on average the experimental group $(\mathrm{M}=1275.53, \mathrm{SD}=206.10)$ spent more time on posttest of problem-solving formulation than the control group $(\mathrm{M}=637.80, \mathrm{SD}=89.36)$. The results of the independent $\mathrm{t}$-test $(\mathrm{t}$ $(58)=15.54, \mathrm{P}=.000<.05 \mathrm{r}=.89$ it represents a large effect size) indicate that there is a significant difference between the experimental and control groups' time spent on the posttest of problem-solving formulation.

Regarding the frequency of solving formulation problems, an analysis of chi-square was run to compare the experimental and control groups' frequency of solving formulation problems on pretest and posttest phases. The results of the chi-square $(\mathrm{x}(1)=1.79, \mathrm{P}=.180>.05)$ indicate that there is not any significant difference between the experimental and control groups' frequency of solving formulation problems on pretest and posttest phases.

A multivariate ANOVA (MANOVA) was run to compare the experimental and control groups' means on pretests of problem-solving formulation as a function of the type of problems (i.e. the compensatory/ upgrading class of problems) they pose themselves in order to prove that they were homogenous in terms of the problem-solving formulation as a function of the type of problems (i.e. the compensatory/ upgrading class of problems).

Before reporting the main results it should be noted that the assumption of homogeneity of variances - as tested through the Levene's F-values ( all higher than .05) - and the assumption of homogeneity of covariance - as tested through the Box's test(The Box's M-value of 2.66 is not significant $(\mathrm{P}=.464>.05)$ - were met.

Based on the results it can be concluded that there are significant differences between the experimental and control groups means on the posttests of upgrading and compensatory class of problems $(\mathrm{F}(2,57)=986.92, \mathrm{P}=.000<.05$, Partial $\eta 2=.97$ it represents a large effect size). The results also show a significant difference between the two groups on upgrading $(\mathrm{F}(1,58)=2008.30, \mathrm{P}=.000<.05$, Partial $\eta 2=.97$ it represents a large effect size) and compensatory $(\mathrm{F}$ $(1,58)=4.02 ., P=.05=.05$, Partial $\eta 2=.065$ it represents a moderate effect size). Descriptive statistics for the experimental and control groups on the post-tests of upgrading and compensatory class of problems indicate that the experimental group $(\mathrm{M}=41.25)$ shows a higher mean on posttest of upgrading class of problems while the control group $(M=9.83)$ shows a higher mean on posttest of compensatory class of problems.

\section{Conclusion}

Analyzing the quantitative data of this study which included the results of the critical thinking test, the results of the independent t-test indicated the significant difference between the experimental and control groups' mean scores on the post test of critical thinking test. On the average the experimental group $(\mathrm{M}=115.07, \mathrm{SD}=12.96)$ showed a higher mean on the posttest of critical thinking test than control group $(M=103.60, S D=12.71)$. It can be concluded that the treatment of the study -teaching questioning as a critical thinking skill-increased the EFL learners' critical thinking level in the experimental group.

The analysis of the qualitative data of the present study which included the analysis of the transcripts of the participants' think-aloud protocols provided three conclusions.

Firstly, the results of independent t-test comparing the experimental and control groups' time spent on posttest of problem-solving formulation showed a significant difference between the two groups' mean scores. On average the experimental group $(\mathrm{M}=1275.53, \mathrm{SD}=206.10)$ spent more time on posttest of problem-solving formulation than the 
control group $(M=637.80, S D=89.36)$. Thus, it can be concluded that teaching questioning as a critical thinking skill resulted in the increase of the amount of time devoted to solving formulation problems.

Secondly, an analysis of chi-square comparing the experimental and control groups' frequency of solving formulation problems on pretest and posttest phases, showed no significant difference between the two groups on this test $(\mathrm{x}(1)=1.79, \mathrm{P}=.180>.05)$. Thus it can be concluded that teaching questioning as a critical thinking skill does not have any statistically significant effect on the frequency of solving formulation problems.

So far it was concluded that increasing the participants' level of critical thinking through teaching questioning as a critical thinking skill results in devoting more time to solving formulation problems. However, the more important issue is to scrutinize this finding more deeply to understand the exact effect of the treatment of the study on the problemsolving formulation process. To reach this goal, the fourth research question of this study was raised. Results of the analysis of multivariate ANOVA (MANOVA) run for both the pretest and posttest of upgrading and compensatory class of problems shed light on the fourth research question.

The results of multivariate ANOVA (MANOVA) comparing the two groups' means on the posttest of problemsolving formulation as a function of the type of problems (i.e. compensatory/ upgrading class of problems) they pose themselves indicated the significant difference between the two groups' time devoted to these two classes of problems. The results help to come to the conclusion that the experimental group spent more time on the upgrading class of problems while the control group spent more time on the compensatory class of problems.

Considering all the above mentioned results and also the results of construct validity, it can be concluded that the compensatory class of problems and critical thinking are two distinct traits; while the problem-solving formulation and upgrading class of problems are not two distinct factors as the results also showed the effectiveness of the treatment on both traits.

\section{REFERENCES}

[1] Bloom, B.S. (Ed.) (1956). Taxonomy of educational objectives: Cognitive domain. New York: David Mckay Company.

[2] Bensely, D.A. (1998). Critical thinking in psychology: A unified skill approach. Pacific Grove, CA: Brooks/ Cole Publishing Company.

[3] Brown, H. D. (2001). Teaching by principles: An interactive approach to language pedagogy (2nd ed.). New York: Longman.

[4] Dalton, J., Smith, D. (1986). Extending children's special abilities: Strategies for primary classroom. Retrieved July 26, 2012 , from http://www.teachers.ash.org.au/researchskills/Question.htm.

[5] Dyson, A. H. \& Freedman, S. (1990). On teaching writing: A review of the literature. Research in Teaching of English Language Arts. Occasional paper No.20, 1-49.

[6] Flower, L. \& Hayes, J. R. (1977). Problem solving strategies and the writing process. College English, 39, 449-461.

[7] Flower, L. \& Hayes, J. R. (1981 a). A cognitive process theory of writing. College Composition and Communication, 32, 365387.

[8] Freedman, S., Dyson, A.H., Flower, L. \& Chafe, W. (1987). Research in writing: Past, present, and future. Research in the Teaching of English, 15, 1-16.

[9] Hamp-Lynos, L. and Kroll, B. (1997). TOEFL 2000- writing: Composition, community, and assessment. (TOEFL Monograph Series Report No.5).Princeton, NJ: Educational Testing Service. Retrieved August 22, 2012, from, http://originwww.ets.org/Media/Research/pdf/RM-00-05.pdf.

[10] Munchón, R., Rosa, M. (2001). Trends in the conceptualizations of second language composing strategies: A critical analysis. IJES, 1(2), 2001, p.p. 47-70.

[11] Roca de Larios, J. \& Murphy, L. (2001). Some steps towards a socio- cognitive interpretation of second language composition processes. IJES, VOL. 1(2), 2001. P.P. 25-45.

[12] Roca de Larios, J., Murphy, L. \& Munchón, R. M. (1999). The use of restructuring strategies in EFL writing: A study of Spanish learners of English as a foreign language. Journal of Second Language Writing. 8(1), 13-44.

[13] Roca de Larios, J., Murphy, L. \& Munchón, R. M. (2006). Generating text in native and foreign language writing: A temporal analysis of problem- solving formulation processes. The Modern Language Journal, 90, I, (2006). p. 100-114.

[14] Sasaki, M. (2000). Towards an empirical model of EFL writing processes: An explanatory study. Journal of Second Language Writing, 9, 259-291.

[15] Sasaki, M. \& Hirose, K. (1996). Explanatory variables for EFL students' expository writing. Language Learning, 46(1), 137174.

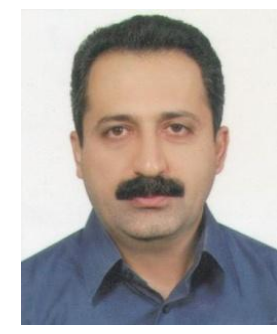

Amir Marzban is an assistant professor of TESOL at Islamic Azad University, Qaemshahr branch. His research interests include conversation analysis, L2 reading \& writing, CALL, and teacher education. He has published in both Iranian and International journals and also has presented in many international conferences. 


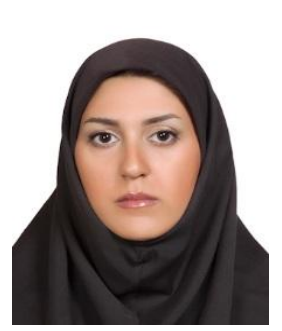

Zahra Jalili was born in Tehran, Iran in 1985. She holds a M.A in TEFL from Islamic Azad University, Mazandaran Science and Research Branch. Her research interests include L2 writing and speaking, testing and statistics, kids language learning and teaching and teacher education. 